\title{
Synthesis of polyethene-graft-polystyrene copolymers from linear polyethene-containing cyclopropane rings
}

\author{
Stefania Pragliola, Piefrancesco Stabile, Mariagrazia Napoli and Pasquale Longo
}

An efficient procedure to produce polyethene-graft-polystyrene (E-C3-graft-PS) copolymers by simple thermal treatment at $200{ }^{\circ} \mathrm{C}$ of polyethene (PE)-containing cyclopropane ring units (E-C3) in the presence of a high excess of styrene is reported. The high treatment temperature likely induces the breaking of the constrained cyclopropane rings, leading to the formation of radicals on the PE chains. The presence of styrene during the thermal treatment allows the formation of side polymer chains on the starting materials and, consequently, of graft copolymers. The graft copolymers that were obtained are efficient compatibilizers for polymer blends as was determined from scanning electron micrographs, which were used to examine the bulk morphologies of two blends: one composed of 50/50 PE and polystyrene (PS), and the other of 49/49/2 PE, PS and E-C3-graft-PS.

Polymer Journal (2011) 43, 714-717; doi:10.1038/pj.2011.42; published online 1 June 2011

Keywords: blends; compatibilizers; cyclopropane rings; graft copolymers

\section{INTRODUCTION}

The incorporation of functional monomers into polyethene (PE) chains is one of the main academic and industrial goals of polymer chemistry because it allows the synthesis of new materials with many attractive properties. ${ }^{1}$ Several polymerization methods have been developed to incorporate different monomers, such as styrene and methylmethacrylate, into PE chains. Nevertheless, because of the general inability of a single initiator to polymerize both ethene and functional monomers, graft and block copolymers usually have been synthesized by postpolymerization processes, including free-radical initiator, living anionic and transition metal-catalyzed polymerizations. ${ }^{2-7}$

As it has been reported in the literature, PEs containing controlled amounts of methylene-1,2-cyclopropane and methylene-1,2-cyclopentane units (hereafter called E-C3) can be obtained by the polymerization of ethene with 1,3-butadiene using rac- $\left[\mathrm{CH}_{2}\right.$ (3-tert-butyl1-indenyl $\left.)_{2}\right] \mathrm{ZrCl}_{2}$ activated by methylalluminoxane as a catalyst. ${ }^{8-12}$ These PEs are technologically relevant because the presence of reactive cyclopropane rings in the chains discloses the possibility to obtain polymers with different properties. ${ }^{13,14}$ For example, in a recent study by our group, we showed that it is possible to produce crosslinked $\mathrm{PE}$ by simple thermal treatments of E-C3 copolymers in the temperature range of $160-200{ }^{\circ} \mathrm{C} .13$ The process takes place in a feasible time $(1 \mathrm{~h})$ without using any initiator and without loss of polymer crystallinity; it produces crosslinked $\mathrm{PE}$ in conditions that can be compatible with industrial fabrication processes. The formation of crosslinking is generated by the breaking of the highly tensioned cyclopropane rings with the subsequent generation of radicals.

The thermal treatment of E-C3 copolymers up to $160{ }^{\circ} \mathrm{C}$ in the presence of functional monomers able to give radical polymerization can also produce graft copolymers of PE. In this respect, it is worth noting that graft copolymers are largely used for the compatibilization of immiscible polymer blends. ${ }^{15-21}$ In the past decade, investigations on polymer blends have intensified significantly because they offer a convenient alternative to developing totally new polymers. Polymer blends can be tailored to meet the requirements of specific applications. However, the ability to produce blends with a desired combination of properties of the individual components depends on the compatibility of the system. Unfortunately, most polymers are immiscible, and as a consequence, the majority of polymer blends are weak. Mechanical failure usually arises from low molecular attractive forces between the dispersed phase and matrix. However, the properties of immiscible blends are improved if the interfacial zone is strengthened by incorporating an interfacially active graft copolymer.

In this paper, the synthesis of graft copolymers obtained simply by heating E-C3 copolymer samples in the presence of monomers such as styrene is reported. The characterization by ${ }^{13} \mathrm{C}$ nuclear magnetic resonance (NMR), gel permeation chromatography (GPC) and differential scanning calorimetry (DSC) analysis of these products is also shown. Furthermore, polyethene-graft-polystyrene copolymers (E-C3-graft-PS) were tested as compatibilizers for polymer blends. The investigation into the morphology of the compatibilized blends was performed with scanning electron microscopy (SEM).

\section{EXPERIMENTAL PROCEDURE}

General procedure

All operations were performed under a nitrogen atmosphere with conventional Schlenk line techniques. Toluene was refluxed over sodium diphenylketyl for $48 \mathrm{~h}$ and distilled before use. Dichloromethane was refluxed over calcium 
hydride and distilled before use. 1,3-Butadiene, ethene, styrene, 7-tetradecene and diiodomethane were purchased from Aldrich (Milano, Italy). 1,3-Butadiene and ethene were used without further purification, whereas styrene was distilled over calcium hydride before use. Methylalluminoxane was purchased from Witco Specialties Italia S.P.A. (Milano, Italy) and used as a solid after distillation of solvent. Rac- $\left.\left[\mathrm{CH}_{2} \text { (3-tert-butyl-1-indenyl) }\right)_{2}\right]-\mathrm{ZrCl}_{2}$ was synthesized according to the literature. ${ }^{22}$

\section{E-C3 polymer synthesis}

In a $250-\mathrm{ml}$ glass autoclave maintained at $20^{\circ} \mathrm{C}, 100 \mathrm{ml}$ of toluene, methylalluminoxane $\left(580 \mathrm{mg}, 1.0^{-2} \mathrm{~mol}\right.$, based on $\left.\mathrm{Al}\right), 1,3$-butadiene $\left(0.65 \mathrm{moll}^{-1}\right.$ and the catalyst $\left(2.0^{-5} \mathrm{~mol}\right)$ were introduced. The autoclave was fed with ethene ( 5 a.t.m.) and kept under magnetic stirring over the run. It was then vented and the copolymer was recovered by precipitation with ethanol/ $\mathrm{HCl}$ and dried under reduced pressure at room temperature.

\section{E-C3-graft-PS copolymer synthesis}

One gram of E-C3 polymer sample containing $1.1 \%(\mathrm{~mol} / \mathrm{mol})$ of cyclopropane units and $20 \mathrm{ml}$ of styrene were put in a vial under nitrogen $\left(\mathrm{N}_{2}\right)$. The vial was sealed and kept in an oven at $200{ }^{\circ} \mathrm{C}$ for $2 \mathrm{~h}$. The sample was recovered by precipitation with ethanol and dried under reduced pressure at room temperature.

\section{Synthesis of 1,2-di- $n$-hexyl-cyclopropane}

1,2 -Di- $n$-hexyl-cyclopropane was synthesized by the following procedure. In a two-neck, $500-\mathrm{ml}$ flask with stirring bar, $200 \mathrm{ml}$ of dichloromethane, $20 \mathrm{~g}$ $(0.103 \mathrm{~mol})$ of 7 -tetradecene and $41.5 \mathrm{~g}(0.155 \mathrm{~mol})$ of diiodomethane were introduced sequentially. The flask was cooled to $0^{\circ} \mathrm{C}$. Then $21.2 \mathrm{ml}$ of a solution of $\mathrm{Al}\left(\mathrm{CH}_{2} \mathrm{CH}_{3}\right)_{3}(0.155 \mathrm{~mol})$ was added dropwise. The mixture was stirred at room temperature for $24 \mathrm{~h}$ after the final addition, and then, $200 \mathrm{ml}$ of dichloromethane was added. Then $21.7 \mathrm{~g}(0.517 \mathrm{~mol})$ of $\mathrm{NaF}$ was introduced, and the flask was cooled to $0{ }^{\circ} \mathrm{C}$ again. A volume of $25 \mathrm{ml}$ of water was carefully added to the mixture, which was then stirred for $30 \mathrm{~min}$ and then filtered. The solid was recovered by filtration and extracted with dichloromethane $(50 \mathrm{ml}$ three times). The organic phase was concentrated under reduced pressure to yield an oily product. The product yield was $>99 \%$.

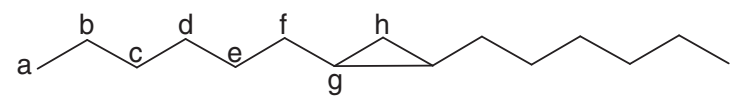

${ }^{13} \mathrm{C}$ NMR (300 MHz, $\mathrm{CDCl}_{3}$, p.p.m.): $\mathrm{C}_{\mathrm{a}(\text { cis, trans })}: \delta 14.39 ; \mathrm{C}_{\mathrm{b}(\text { cis, trans })}: \delta 23.01$; $\mathrm{C}_{\mathrm{c}(\text { cis, trans })}: \delta 32.28 ; \mathrm{C}_{\mathrm{d}(\text { trans })}: \delta 29.68 ; \mathrm{C}_{\mathrm{d}(\text { cis })}: \delta 29.53 ; \mathrm{C}_{\mathrm{e}(\text { trans })}: \delta 29.98 ; \mathrm{C}_{\mathrm{e}(c i s)}:$ $\delta$ 28.88; $\mathrm{C}_{\mathrm{f}(\text { trans })}: \delta$ 34.68; $\mathrm{C}_{\mathrm{f}(\text { cis })}: \delta 30.50 ; \mathrm{C}_{\mathrm{g}(\text { trans })}: \delta$ 19.06; $\mathrm{C}_{\mathrm{g}(\text { cis })}: \delta 16.05 ;$ $\mathrm{C}_{\mathrm{h}(\text { trans })}: \delta 11.69 ; \mathrm{C}_{\mathrm{h}(\text { cis })}: \delta 11.18$.

\section{NMR measurements}

${ }^{13} \mathrm{C}$ NMR polymer spectra were recorded on a Bruker Avance 300 spectrometer (Bruker Italia, Milano, Italy) operating at $75 \mathrm{MHz}$ and $393 \mathrm{~K}$ and using an inverse-gated-decoupling mode to eliminate the nuclear Overhauser effect. This allows the assumption that the areas of the resonances of the ${ }^{13} \mathrm{C}$ NMR spectra are proportional to the amounts of the different carbons. The following ${ }^{13} \mathrm{C}$ NMR acquisition parameters were used: acquisition time $=1.2 \mathrm{~s}$, pulse delay $\mathrm{D} 1=4 \mathrm{~s}$ and pulse angle $\mathrm{P} 1=8.25 \mu \mathrm{s}\left(90^{\circ} \mathrm{C}\right)$. The samples were prepared by dissolving $40 \mathrm{mg}$ of polymer in $0.5 \mathrm{ml}$ of tetrachlorodideuteroethane. Hexamethyldisiloxane was used as internal chemical shift reference.

The percent amounts of cyclic units (cyclopropane and cyclopentane) in the E-C3 polymers were calculated by ${ }^{13} \mathrm{C}$ NMR. The method is described in detail in Pragliola et al. ${ }^{8}$

\section{Thermal analysis}

Calorimetric measurements were performed on a DSC 2920 apparatus manufactured by TA Instruments Italy (Milano, Italy) with inflowing $\mathrm{N}_{2}$ and a heating rate of $10{ }^{\circ} \mathrm{C} \mathrm{min}^{-1}$. The melting temperatures and the heats of fusion were evaluated from the peak temperatures and the areas of the maxima of the appropriate endotherms. These data are related to the second heating runs.

\section{Gel permeation chromatography}

The molecular weight distribution and polydispersity index were estimated by GPC at $140^{\circ} \mathrm{C}$ using 1,2,4-trichlorobenzene as the solvent and narrow molecular weight distribution polystyrene (PS) standard samples as the reference. The measurements were performed on PLGPC210 with four PL-Gel Mixed A Columns, a refractive detector and a DM400 data manager (Viscotek, Malvern Instruments Ltd, Worcestershire, UK).

\section{RESULTS}

\section{E-C3-graft-PS copolymers}

E-C3-graft-PS copolymers were obtained by thermal treatment of an E-C3 sample at $200{ }^{\circ} \mathrm{C}$ for $2 \mathrm{~h}$ in the presence of a high excess of styrene. Exhaustive extractions of the products with 2-butanone allowed the obtained graft copolymers to separate from amorphous PS, which was possibly formed by radicals.

${ }^{13} \mathrm{C}$ NMR, DSC and GPC analysis were used to characterize the materials.

The starting E-C3 sample used for the thermal treatment in the presence of styrene contains close to $1.1 \%$ cyclopropane and $0.5 \%$ cyclopentane rings. The cyclopropane/cyclopentane ratio in this sample was estimated to be about 2.2.

Figure 1a shows the ${ }^{13} \mathrm{C}$ NMR spectrum of the starting E-C3 sample. In Figure $1 \mathrm{~b}$, the ${ }^{13} \mathrm{C}$ NMR spectrum of the 2-butanone insoluble fraction of the E-C3-graft-PS copolymer sample is shown. Here, in addition to the resonances relative to the E-C3 polymer sample, signals relative to styrene homosequences are also present. Unfortunately, resonances attributable to the junction carbons between PS and E-C3 polymer chains are not detectable because of their small size and overlap with other peaks present in the spectrum.

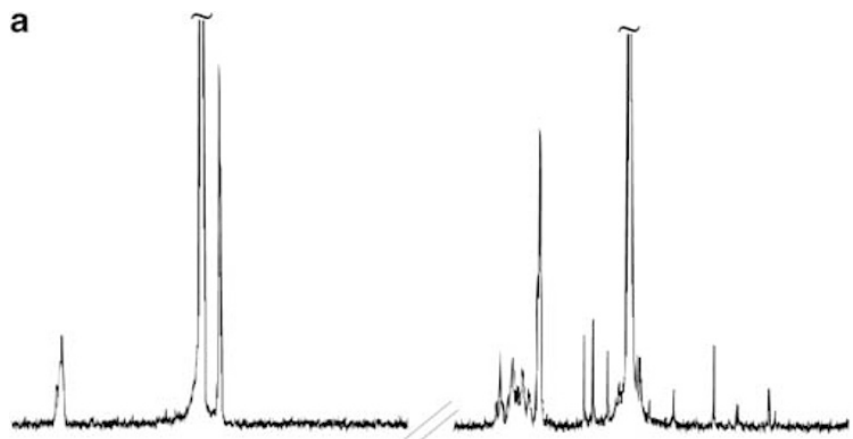

b

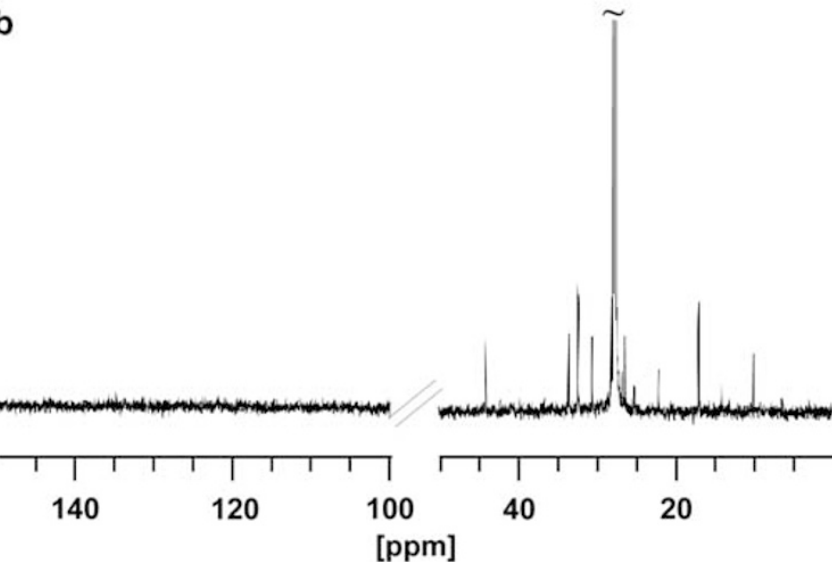

Figure $1{ }^{13} \mathrm{C}$ Nuclear magnetic resonance spectra of E-C3 (a) and E-C3graft-PS (b) polymer samples. Tetrachlorodideuteroethane was used as a solvent. Hexamethyldisiloxane scale. E-C3-graft-PS, polyethene-graftpolystyrene. 
The resonances of all recognized structural units were assigned on the basis of the data reported in the literature for carbons in similar environments and are reported in Table 1.

Comparing the intensities of the signals relative to the cyclopropane and cyclopentane units of the two spectra of Figure 1, the cyclopropane ring/cyclopentane ring ratio is $22 \%$ lower in the E-C3-graft-PS sample than in the starting sample. This is clearly shown also by a visual comparison of the heights of resonances 3 and 8 in Table 1 . The amount of enchained styrene units was evaluated by ${ }^{13} \mathrm{C} N M R$ and is close to $20 \%$.

The DSC scan of the E-C3-graft-PS sample shows that the melting temperature $\left(T_{\mathrm{m}}=115^{\circ} \mathrm{C}\right)$ remains essentially identical to that of the untreated E-C3 sample. Because of the presence of atactic styrene homosequences in the E-C3-graft-PS sample, a significant decrease in the melting enthalpy per gram of polymer is seen instead.

The copolymeric nature of the E-C3-graft-PS sample was confirmed by GPC analysis, which showed mono-modal curves both for the starting E-C3 and E-C3-graft-PS samples. Moreover, the measured molecular weight of the E-C3-graft-PS $\left(M_{\mathrm{w}}=7.8 \times 10^{5}\right)$ sample was higher than that of the untreated starting E-C3 sample $\left(M_{\mathrm{w}}=3.2 \times 10^{5}\right)$. A clear increase in the polydispersity index was also detected for

Table $1{ }^{13} \mathrm{C}$ Nuclear magnetic resonances of the carbons of all recognized structures of E-C3-graft-PS copolymers

Chemical shifta
Monomeric units

Abbreviation: E-C3-graft-PS, polyethene-graft-polystyrene.

aThe primed numbers refer to cis configuration structures.

bSee Pragliola et al. ${ }^{8}$.

'See Matsuzaki et al..$^{23}$
E-C3-graft-PS sample with respect to that of starting E-C3 sample (E-C3: $M w / M n, M W D=2.1$; E-C3-graft-PS: $M w / M n, M W D=4.0$ ).

\section{Model compound: 1,2-di- $n$-hexyl-cyclopropane}

To carefully investigate how the reactivity of cyclopropane rings in the E-C3 copolymer can promote the copolymerization of styrene, a model compound of E-C3, 1,2-di- $n$-hexyl-cyclopropane (see Experimental Procedure) was synthesized and used in copolymerization tests with styrene. The reaction was carried out in a sealed vial at $200{ }^{\circ} \mathrm{C}$ for $2 \mathrm{~h}$.

${ }^{13} \mathrm{C}$ NMR analysis of the product allowed identification of resonances relative to the junction carbons between the PS chain and the model compound that were not detectable in the E-C3/Sty copolymers. Resonances at 32.49 and 25.37 p.p.m., which were attributed to carbons $\alpha$ and $\beta$ of Scheme 1 were found in the product insoluble fraction. The peaks relative to the other junction carbons were not identified because they overlap with hydrocarbon chain signals.

\section{E-C3-graft-PS polymer as a compatibilizer in a polymer blend}

One of the possible applications for a graft copolymer is a compatibilizer for immiscible polymer blends. The E-C3-graft-PS copolymers have been tested as a compatibilizer for a PE-PS blend. The experiment was carried out to increase miscibility and improve dispersion, enhancing interfacial adhesion between the phases of PE and PS. Therefore, two PE/PS blends without and with the addition (2\%) of E-C3-graft-PS were prepared by dissolving the components in $20 \mathrm{ml}$ refluxing 1,2-dichlorobenzene under nitrogen. After the polymer mixture had formed a clear solution, the blend was precipitated by pouring the solution into cold ethanol. The blends were dried under vacuum, melt-pressed at $200{ }^{\circ} \mathrm{C}$ and quickly quenched at $0{ }^{\circ} \mathrm{C}$ to form a 2-mm thick film.

The obtained films were cryo-fractured in liquid nitrogen, and the surface of the edges was observed through SEM to examine the bulk morphologies. Figure 2 reports the SEM images of the two blends composed of 50/50 PE and PS (see Figure 2a) and 49/49/2 of PE, PS and E-C3-graft-PS (see Figure 2b). In the homopolymer blend, the fractured surface indicates non-uniform dispersion of the two components (see Figure 2a). However, when a small amount of E-C3-graft-PS copolymer was added, the morphology of the blend was markedly improved (see Figure 2b). In fact, the image of the latter blend is more uniform and regular than the former, and the domain has smaller sizes. This result clearly indicates that E-C3-graft-PS copolymers are able to improve the miscibility between $\mathrm{PE}$ and PS.

\section{CONCLUSIONS}

We have described a simple, inexpensive, efficient and industrially compatible procedure able to produce E-C3-graft-PS copolymers by simple thermal treatment of a PE containing cyclopropane and cyclopentane ring units at $200{ }^{\circ} \mathrm{C}$ in the presence of a high excess of

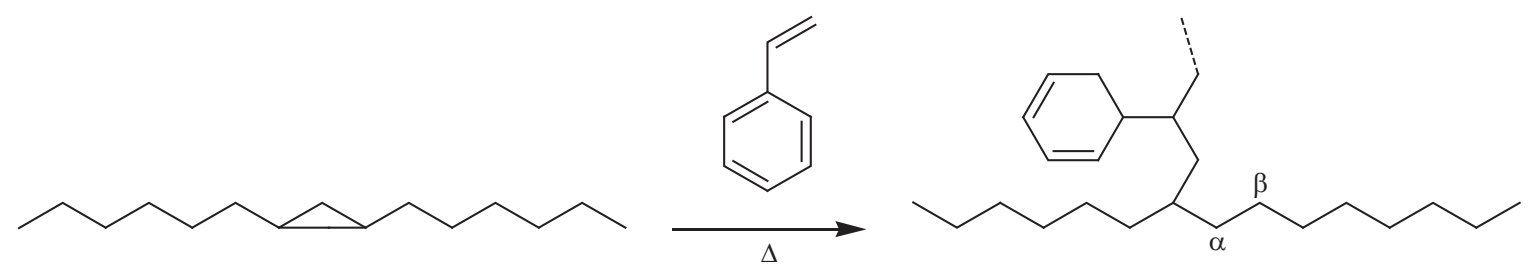

Scheme 1 Reaction between model compound 1,2-di- $n$-hexyl-cyclopropane and styrene. 
a

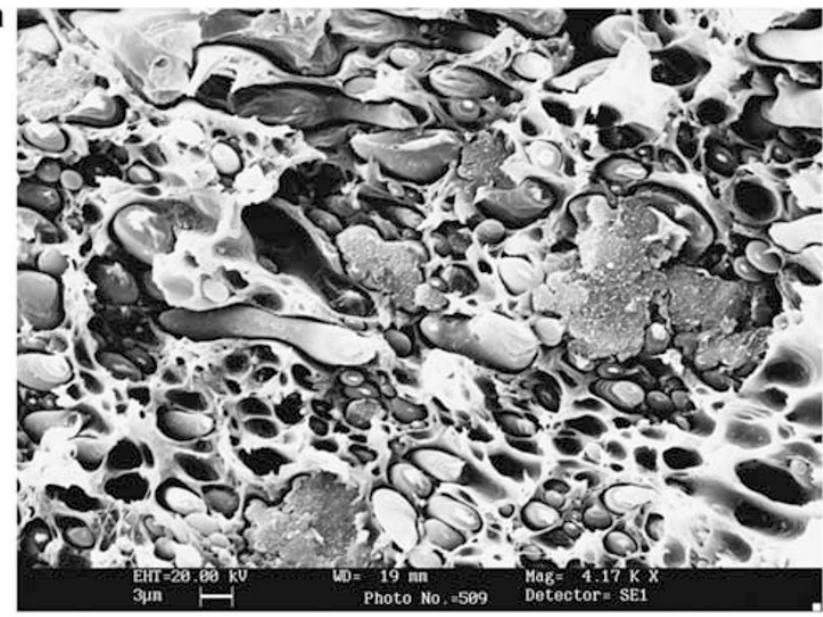

b

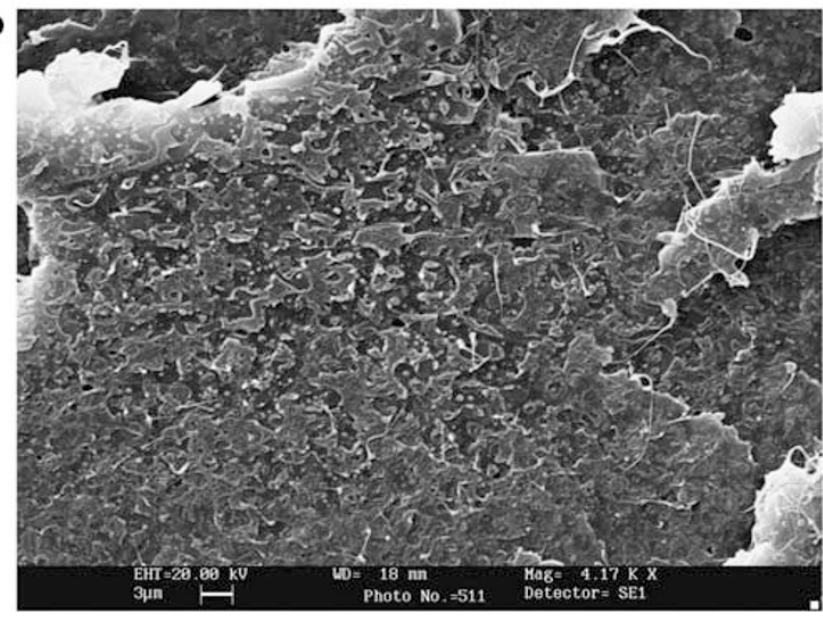

Figure 2 Scanning electron micrographs of the cross-section of two polymer blends: (a) two homopolymers with polyethene (PE)/polystyrene (PS) $=50 / 50$ and (b) two homopolymers, PE and PS, and $2 \mathrm{wt} \%$ of polyethene-graftpolystyrene polymer sample.

styrene. The high treatment temperature likely induces the breaking of the constrained cyclopropane rings, leading to the formation of radicals on the PE chains. The presence of suitable monomers such as styrene during the thermal treatment can allow the formation of side polymer chains on the starting materials.

To carefully investigate how the reactivity of cyclopropane rings in the E-C3 copolymer can promote the copolymerization of styrene, a model compound of E-C3, 1,2-di- $n$-hexyl-cyclopropane, was synthesized and used in copolymerization tests with styrene.

The graft copolymers obtained are efficient compatibilizers for polymer blends. SEM was used to examine the bulk morphologies of two blends composed of 50/50 PE and PS and 49/49/2 PE, PS and E-C3-graft-PS. In the homopolymer blend, the fractured surface indicates non-uniform dispersion of the two components. By contrast, when a small amount (2\%) of E-C3-graft-PS copolymer was added, the morphology of the blend was markedly improved.

It is worth noting that this synthetic strategy is applicable to all monomers able to polymerize by radicals. This process safeguards the natural environment because the graft copolymers are obtained without solvent and initiators and only require thermal treatments of reagents.

Currently, further experimental studies that involve different monomers, such as methylmethacrylate, are in progress.

\section{ACKNOWLEDGEMENTS}

We thank Dr Patrizia Oliva and Dr Ivano Immediata of the Department of Biology and Chemistry at the University of Salerno for their technical assistance. Financial support from the 'Ministero dell'Università e della Ricerca Scientifica e Tecnologica' (PRIN 2008) is gratefully acknowledged.

1 Utracki, L. A. (ed.) Polymer Blends Handbook (Springer, Berlin, 2003).

2 Chung, T. C. \& Rhubright, D. Synthesis of polypropylene-graft-poly(methyl methacrylate) copolymers by the borane approach. Macromolecules 26, 3467-3471 (1993).

3 Chung, T. C., Lu, H. L. \& Ding, R. D. Synthesis of Polyethylene-g-polystyrene and polyethylene-g-poly(p-methylstyrene) graft copolymers. Macromolecules $\mathbf{3 0}$, 1272-1278 (1997).

4 Lipponen, S. \& Seppiala, J. Functionalization of polyethylene with silane comonomers. J. Polym. Sci. Part A Polym. Chem. 40, 1303-1308 (2002).

5 Shiono, T., Kurosawa, H., Ishisa, O. \& Soga, K. Synthesis of polypropylenes functionalized with secondary amino groups at the chain ends. Macromolecules 26, 20852089 (1993).

6 Kesti, M. R., Coates, G. W. \& Waymouth, R. M. Homogeneous Ziegler-Natta polymerization of functionalized monomers catalyzed by cationic Group IV metallocenes. J. Am. Chem. Soc. 114, 9679 (1992).

7 Johnson, L. K., Mecking, S. \& Brookhart, M. Copolymerization of ethylene and propylene with functionalized vinyl monomers by palladium(II) catalysts. J. Am. Chem. Soc. 118, 267 (1996).

8 Pragliola, S., Milano, G., Guerra, G. \& Longo, P. Stereoselective cyclopropanation by cyclocopolymerization of butadiene. J. Am. Chem. Soc. 124, 3502 (2002)

9 Longo, P., Pragliola, S., Milano, G. \& Guerra, G. E Stereoregular 1,1 and 1,3 constitutional units from 1,3-butadiene in copolymerizations catalyzed by a highly hindered C2 symmetric metallocene. J. Am. Chem. Soc. 125, 4799 (2003).

10 Longo, P., Pragliola, S. \& Guerra, G. Ethylene copolymers having cyclopropyl rings in the main chain WO 02/098936 Al (2002).

11 Pragliola, S., Costabile, C., Magrino, M., Napoli, M. \& Longo, P. Ethene/1,3-butadiene copolymerization in the presence of rac-(CH2-(3-tert-butyl-1-indenyl)2) $\mathrm{ZrCl}$ / MAO catalytic system: study of the polymerization mechanism by using $13 \mathrm{C}$-labeled 1,3-butadiene. Macromolecules 37, 238 (2004).

12 Longo, P., Napoli, M., Pragliola, S., Costabile, C., Milano, G. \& Guerra, G. Butadiene insertion and constitutional units in ethene copolymerizations by $\mathrm{C} 2$-symmetric metallocenes. Macromolecules 36, 9067 (2003).

13 Cavallo, G., Venditto, V., Annunziata, L., Pragliola, S., Longo, P. \& Guerra, G. Thermal crosslinking of ethene copolymers containing 1,2-cyclopropane units. Polymer 46, 2847 (2005).

14 Cavallo, G., Venditto, V., Pragliola, S., Longo, P. \& Guerra, G. Infrared spectra and thermal reactivity of ethene copolymers containing 1,2-cyclopropane units. Polymer 47, 2274 (2006).

15 Paul, R. D. \& Newman, S. Polymer Blends (Academic Press Inc.: New York, 1978).

16 Thomas, E. L. Materials Science and Technology: A Comprehensive Treatment Vol. 12 (eds R.W. Cahn et al.) 251 (VCH Publishers, Weinheim, 1991).

17 Olabisi, O., Robeson, L. M. \& Shaw, M. T. Polymer-Polymer Miscibility (Academic Press Inc, New York, 1979).

18 Riess, G. \& Jolivet, Y. Polyblends and Composites Vol. 142 (ed. Platzer, N.A.J.) (ACS Advances in Chemistry Series, American Chemical Society, Washington, DC, 1975).

19 Fayt, R., Hadjiandreou, P. \& Teyssie, P. Molecular design of multicomponent polymer systems. VII. Emulsifying effect of poly(ethylene-b-styrene) copolymer in high-density polyethylene/polystyrene blends. J. Polym. Sci. Polym. Chem. 23, 337 (1985).

20 Edgecombe, B. D., Stein, J. A., Fréchet, J. M. J., Xu, Z. \& Kramer, E. J. The role of polymer architecture in strengthening polymer-polymer interfaces: a comparison of graft, block, and random copolymers containing hydrogen-bonding moieties. Macromolecules 31, 1292 (1998).

21 Eastwood, E. A. \& Dadmun, M. D. Multiblock copolymers in the compatibilization of polystyrene and poly(methyl methacrylate) blends: role of polymer architecture. Macromolecules 35, 5069 (2002).

22 Resconi, L., Balboni, D., Baruzzi, G. Fiori, C., Guidotti, S Mercandelli, P. \& Sironi, A. Rac-[methylene(3-tert-butyl-1-indenyl)2]ZrCl2: a simple, high-performance zirconocene catalyst for isotactic polypropene. Organometallics 19, 420 (2000).

23 Matsuzaki, K., Uryu, T. \& Asakura, T. NMR Spectroscopy and Stereoregularity of Polymers (Japan Scientific Societies Press, Tokyo Karger, 1996). 